ISSN 1518-3483

Licenciado sob uma Licença Creative Commons

\title{
O elearning em estabelecimentos prisionais: possibilidades e limites para a inclusão digital e justiça social ${ }^{1}$
}

\section{The eLearning in prison: possibilities and limits to digital inclusion and social justice}

\section{El eLearning en las prisiones: posibilidades y limitaciones para la inclusión digital y la justicia social}

\footnotetext{
Angélica Maria Reis Monteiro ${ }^{[\mathrm{a}]}$, José António Moreira ${ }^{[\mathrm{b}]}$, Carlinda Leite ${ }^{[\mathrm{a}]^{*}}$

[a] Faculdade de Psicologia e de Ciências da Educação da Universidade do Porto, Porto, Portugal

[b] Departamento de Educação e Ensino a Distância da Universidade Aberta, Portugal
}

1 Este trabalho é financiado parcialmente por Fundos Nacionais através da FCT - Fundação para a Ciência e a Tecnologia no âmbito do projeto estratégico do CIIE, com a referência "SFRH/ BPD/92427/2013". O projeto inclui um estudo de pós-doutoramento financiado pela Fundação Ciência e Tecnologia por fundos nacionais do Ministério da Educação e Ciência e pelo Fundo Social Europeu através do POCH - Programa Operacional do Capital Humano (ref. SFRH/BPD/92427/2013). No presente estudo, escrito em português de Portugal, foi preservada a grafia do país de origem.

AMRM: Doutora em ciências da Educação, e-mail: armonteiro@fpce.up.pt JAM: Doutor em ciências da Educação, e-mail: jmoreira@uab.pt CL: Doutora em ciências da Educação, e-mail: carlinda@fpce.up.pt 


\title{
Resumo
}

As mudanças decorrentes do progresso tecnológico, característico da globalização deram origem a uma "nova sociedade" baseada na informação e no conhecimento, que gera, inevitavelmente, novas desigualdades educativas, mais evidentes em grupos menos favorecidos e em situação de exclusão social, como é o caso das pessoas em situação de reclusão. Este fato justifica que, em contexto prisional, para além da garantia do direito à educação, seja preciso ter em atenção a qualidade da formação no que diz respeito ao desenvolvimento de competências-chave para a participação na sociedade digital e em rede. Este artigo aborda o processo de formação num estabelecimento prisional português, com recurso ao elearning, analisando o contributo deste procedimento para a promoção da justiça social. Neste sentido, são apresentadas as vantagens e as limitações desta modalidade de aprendizagem a partir da percepção de formandas reclusas. Os dados foram recolhidos através de um questionário e de um focus group, e foram analisados através de análise de conteúdo. Como principais resultados apontam-se, ao nível de justiça social, o aumento da oportunidade de acesso e de participação em ambientes digitais. Como vantagens da formação, as participantes expressaram, ainda, o aumento da autoestima e o desenvolvimento de competências de aprendizagem. Por outro lado, a desmotivação e a dificuldade de conciliação da formação com a rotina diária foram os principais obstáculos identificados.

Palavras-chave: Educação prisional. Elearning. Inclusão digital. Justiça social.

\begin{abstract}
The world is experiencing an accelerated transformation process caused by the expansion of world capitalism and technological progress, typical of globalisation. These transformations have led to a "new society" based on information and knowledge, which will inevitably generate new educational inequalities that are more evident in less favoured and socially excluded groups, as in the case of prisoners. This fact justifies that, in a prison context, in addition to ensuring the right to education, attention must be paid to the quality of education as regards the development of key skills for participating in a digital and networked society. This article addresses the training process in a Portuguese prison using elearning, with a special focus on the drivers of digital inclusion, aiming for social justice.
\end{abstract}


The paper also presents the advantages and limitations of this type of learning based on the understanding of female prison students. Data were collected through a questionnaire and a focus group, and were analysed through the content analysis technique. The main results include, in terms of social justice, more opportunities to access and participate in digital environments, conducive to inclusion. As for the advantages of training, the participants mentioned the increased self-esteem and the development of learning skills. On the other hand, the main obstacles identified were demotivation and the difficulty in balancing training with their daily routines.

Keywords: Prison Education. eLearning. Digital Inclusion. Social Justice.

\section{Resumen}

Los cambios del mundo globalizado dieron origen a una "nueva sociedad" basada en la información y en el conocimiento, que genera, inevitablemente, nuevas desigualdades educativas que son más evidentes en grupos menos favorecidos y en situaciones de exclusión social, como es el caso de las personas en situación de reclusión. Este hecho justifica que, en contexto de privación de libertad, más allá de la garantía de derecho a la educación, sea preciso prestar atención a la calidad de la formación en lo que respecta al desarrollo de competencias claves para la participación en la sociedad digital y en la red. Este artículo aborda el proceso de formación en un establecimiento carcelario portugués recurriendo al eLearning, el análisis de la contribución de este a la justicia social. Se presentan además las ventajas y las limitaciones de esta modalidad de aprendizaje a partir de la precepción de formandas reclusas. Los datos fueron recogidos a través de cuestionario y de un focus group, y fueron analizados a través de análisis de contenido. Como principales resultados se apunta a nivel de la justicia social, el aumento de oportunidades de acceso y de participación en ambientes digitales. En cuanto a las ventajas de la formación, las participantes expresaron el aumento de la autoestima y el desarrollo de competencias de aprendizaje. Por otro lado, la desmotivación y la dificultad de conciliación de la formación con la rutina diaria fueron los principales obstáculos identificados.

Palabras clave: Educación prisional. Inclusión digital. Justicia social. 


\section{Introdução}

A União Europeia tem, ao longo dos anos, reforçado medidas que pretendem responder aos desafios impostos pela sociedade de informação, nomeadamente, através do estímulo a políticas sociais e de combate à infoexclusão. Estas políticas têm vindo a concretizar-se em estratégias, das quais são exemplos a Estratégia de Lisboa (CONSELHO DA UNIÃO EUROPEIA, 2000) e a Estratégia Europa 2020 (CONSELHO DA UNIÃO EUROPEIA, 2010). A primeira pretendia "transformar a Europa na economia baseada no conhecimento, mais dinâmica e competitiva do mundo, capaz de garantir um crescimento económico sustentável, com mais e melhores empregos, e maior coesão social" (CONSELHO DA UNIÃO EUROPEIA, 2000, s/p), enquanto; a segunda visa preparar a economia europeia para a próxima década, a partir de três vetores fundamentais de crescimento: crescimento inteligente, crescimento sustentável e crescimento inclusivo.

O crescimento económico e social plasmado nestas estratégias implica necessariamente em investimentos na educação/formação de adultos que permita uma adaptação ao mundo em constante transformação e aos desafios impostos pela globalização. Esta adaptação, na visão dos Estados-membros da União Europeia, dar-se-á através do desenvolvimento das competências-chave para a aprendizagem ao longo da vida, que de acordo com conteúdo veiculado pelo Quadro de Referência Europeu (UNIÃO EUROPEIA, 2006) inclui: comunicação na língua materna; comunicação em línguas estrangeiras; competências matemáticas; competência digital; aprender a aprender; competências sociais e cívicas; espírito de iniciativa; sensibilidade e expressões culturais.

Esta visão de aprendizagem por competências, ainda que passível de crítica, fundamentada pela lógica neoliberalista associada à formação instrumental de adultos, e voltada para a produtividade e o desenvolvimento económico (OECD, 1996), em certa medida está também em linha com os valores universais de igualdade, interculturalidade, respeito pela diversidade e direitos humanos, declarados em Conferências 
Internacionais sobre Educação de Adultos (PREECE, 2011; UNESCO, 2010). Para que se caminhe em prol de uma justiça social é preciso, ao mesmo tempo respeitar a igualdade e os direitos universais - como balizas para a convivência social e a governação democrática - sem perder de vista o reconhecimento das diferenças e das necessidades individuais dos diversos grupos sociais, numa lógica de distribuição equitativa. É também neste sentido que Bolívar (2012, p. 5) refere ${ }^{2}$ que: "o direito à educação está relacionado, como universalização, ao paradigma da igualdade; por sua vez, assegurar o sucesso educativo a todos associa-se ao paradigma da equidade". É tendo em vista estas intenções que o presente artigo aborda o processo de formação num estabelecimento prisional português com recurso ao eLearning. O objetivo principal desta formação é que ela contribua para a inclusão digital das pessoas reclusas, tendo como fim a justiça social (CONNELL, 2012).

Do ponto de vista da sua estrutura, o artigo é composto por um breve enquadramento teórico acerca do eLearning em estabelecimentos prisionais, na sua relação com a inclusão digital e a justiça social, seguido dos procedimentos metodológicos, da apresentação dos principais resultados e das conclusões que o estudo permite tecer, onde se estabelecem ilações entre os conceitos de inclusão digital e justiça social, a nível da educação/formação de adultos.

\section{Inclusão digital, justiça social e formação em contextos prisionais}

O estabelecimento de relações entre os conceitos de inclusão social e de justiça social exige que, em primeiro lugar, se esclareça a visão que se tem da implicação social e pedagógica das tecnologias. Em conformidade com a visão de não neutralidade das tecnologias

2 Tradução dos autores. Original: "El derecho a la educación está vinculado, como universalización, al paradigma de la igualdad; por su parte, asegurar el éxito educativo para todos se asocia al paradigma de la equidad". 
devido às transformações sociais e culturais que lhes têm sido associadas (ABRANCHES, 2014), o recurso aos meios tecnológicos em contexto de educação/formação de adultos, por si só, não é um indicador de qualidade da oferta formativa, nem garante a participação paritária dos sujeitos envolvidos. Muito pelo contrário, caso não haja um olhar atento aos contextos sócio-históricos, aos diferentes percursos de vida e às características individuais, as tecnologias podem funcionar como mais um elemento de reforço à situação de exclusão social de adultos (GORARD; SELWYN, 2005).

De fato, as tecnologias de informação e comunicação (TIC), assim como outros recursos ou métodos de ensino, só serão eficazes para o aumento do acesso e do sucesso educativo de adultos quando, simultaneamente, houver uma preocupação com as questões de justiça social — que é influenciada pelo contexto social e pelas condições históricas da localidade social na qual ela emerge (GAMARNIKOW, 2013).

Autores como Murillo e Hernández (2011), Fraser (2002) e Bolivar (2012) apresentam três concepções de justiça social: como distribuição - a forma em que os bens primários encontram-se distribuídos na sociedade - , como reconhecimento - aceitação das diferenças, relação recíproca de respeito igualitário - e como representação - promoção de acesso e equidade para assegurar a participação na vida social —, sendo que estas três dimensões são interdependentes e indispensáveis para a participação na sociedade (FRASER, 2008).

No mesmo sentido, Ayers, Quinn e Stovall (2009) definiram os seguintes pilares da justiça social: equidade de acesso à educação e aos resultados de aprendizagem; agência para mudar situações de injustiça e literacia social, ou a habilidade de "ler o mundo".

Educar, nesse sentido, significa "dar às pessoas os meios para desenvolver suas habilidades e competências que lhes permitam ler o mundo e, com base nessa análise crítica, saber como enfrentá-lo e autodesenvolver-se, de uma forma digna" (HURTADO, 2005, p. 7). Num mundo altamente tecnologizado, acreditamos que a alfabetização digital seja um imperativo para o desenvolvimento pessoal e para a inclusão 
e participação na "sociedade em rede" (CASTELLS, 2002) de todos e de cada um em particular, com especial ênfase para os grupos sociais menos favorecidos ou em situação de exclusão social, como é o caso das pessoas reclusas.

Com o objetivo de assegurar o direito à educação com qualidade e oferta diversificada de contextos de formação adequados ao nível académico dos reclusos (HAWLEY, MURPHY; SOUTO-OTERO, 2013) nos estabelecimentos prisionais europeus é oferecida formação em contexto formal e não-formal. No entanto, em média, menos de $25 \%$ dos reclusos e reclusas participam de atividades de aprendizagem ao longo da vida, sendo que, segundo Hawley, Murphy e Souto-Otero (2013), "as barreiras mais comuns à participação são a falta de motivação e experiências

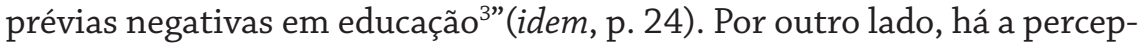
ção de que as barreiras identificadas podem ser ultrapassadas através da diversificação da oferta formativa e da adoção de estratégias de ensino-aprendizagem que envolvem o recurso ao eLearning, ensino a distância, ainda que a utilização das TIC e o acesso à Internet sejam restritos e controlados, o que significa uma barreira para o desenvolvimento de competências digitais das pessoas em situação de reclusão (idem, ibidem, 2013).

O desenvolvimento de competências digitais pode ser considerado uma vertente da inclusão social (WARSCHAUER, 2004) e consiste em proporcionar o acesso às tecnologias, estimulando a capacidade de criar e produzir significados e sentidos nos ambientes digitais (PASSERINO, 2011). O acesso e a sua relação com as questões sociais e comunitárias estão presentes nos princípios básicos da inclusão digital propostos por Muilenburg e Berge (2007), nomeadamente no que diz respeito à necessidade de diminuir as barreiras relativas às TIC e ter em atenção as necessidades locais e comunitárias, a partir de abordagens que recorram a um envolvimento coletivo e participativo.

3 Tradução dos autores. Original "Common barriers to participation are lack of motivation and previous negative experiences of education" 
Tendo presente estes pressupostos no Quadro 1, estabelece-se uma relação entre os indicadores de inclusão digital (UK GOVERNMENT DIGITAL SERVICE, 2014) e a situação dos estabelecimentos prisionais na Europa, a partir dos resultados da "Survey on Prison Education and Training in Europe” (HAWLEY; MURPHY; SOUTO-OTERO, 2013).

Conforme se pode observar no Quadro 1, há elementos relacionados com a vida em reclusão que condicionam ou impedem o desenvolvimento de competências digitais, imprescindíveis para a inclusão digital. Face a este cenário, alguns projetos europeus têm sido desenvolvidos com o objetivo de maximizar o potencial das TIC, como ferramenta de apoio ao eLearning/ensino a distância ou para o desenvolvimento de competências digitais e o aumento da literacia digital das pessoas em situação de reclusão (HAWLEY; MURPHY; SOUTO-OTERO, 2013).

Quadro 1 - Inclusão digital e contexto prisional

\begin{tabular}{|ll}
\hline Indicadores de inclusão digital & $\begin{array}{l}\text { Situação nos estabelecimentos prisionais } \\
\text { europeus }\end{array}$ \\
\hline Acesso & $\begin{array}{l}\text { Acesso restrito ou inexistente às TIC e à } \\
\text { Internet. }\end{array}$ \\
\hline Competências digitais & $\begin{array}{l}\text { Uma grande maioria das pessoas reclusas } \\
\text { possuem baixo nível de escolaridade e de } \\
\text { competências-chave de aprendizagem ao longo } \\
\text { da vida. }\end{array}$ \\
\hline Atitude (motivação/escolha) & $\begin{array}{l}\text { Cerca de } 75 \% \text { das pessoas reclusas na Europa } \\
\text { não participam de ações de formação/ } \\
\text { aprendizagem ao longo da vida, sendo que } \\
\text { a "falta de motivação" aparece com um dos } \\
\text { principais motivos. }\end{array}$ \\
\hline Confiança/Segurança & $\begin{array}{l}\text { Para além das questões de credibilidade dos } \\
\text { meios de ensino a distância, atualmente é } \\
\text { praticamente impossível garantir } 100 \% \text { a } \\
\text { segurança de uso de plataformas digitais } \\
\text { em prisões, ainda que os riscos possam ser } \\
\text { minimizados. }\end{array}$ \\
\hline
\end{tabular}




\section{O elearning em Contexto Prisional}

$\mathrm{Na}$ literatura académica existem diversas definições de eLearning atribuindo-lhe diferentes focos e funções, tais como: tecnologia e processo de separação física entre o professor e os alunos (MASIE, 2006); processo de aprendizagem (ROSENBERG, 2001); meios de comunicação e relação entre fatores humanos e tecnológicos (PAULSEN, 2002). Apesar desta diversidade, o eLearning pode ser considerado como o processo de mediação de aprendizagens feito por meio de um ambiente digital especificamente organizado para o efeito. Para o concretizar, alguns países europeus desenvolveram plataformas online para a mediação da aprendizagem à distância. No que diz respeito à sua utilização em prisões, têm existido projetos-piloto que envolvem parcerias de vários países no sentido de testar soluções e tecer recomendações para o recurso às TIC nestes contextos.

Também em Portugal, a Universidade Aberta — instituição pública de Ensino a Distância e eLearning - conduz um projeto-piloto, procurando testar soluções para o desenvolvimento de um modelo pedagógico inclusivo em eLearning para o Ensino Superior em estabelecimentos prisionais (MOREIRA; NUNES; CAEIRO, 2016).

Como exemplo de outras soluções encontradas que estão a ser concretizadas, pode-se citar as que ocorrem em países europeus, tais como: a Alemanha e Áustria (Elis), o Reino Unido (Virtual Campus) e a Noruega (IFI - "Internet for inmates").

Na Alemanha e na Áustria, a plataforma Elis, segundo Martins (2013), foi desenvolvida em 2004 tendo por objetivo garantir acesso imediato a conteúdos educacionais tanto a estudantes quanto a professores e disponibilizar módulos para a formação profissional em contexto prisional. Sob o ponto de vista técnico, é utilizada uma plataforma open source "ILIAS", adaptada para ir ao encontro dos requerimentos do eLearning em prisões. $\mathrm{O}$ acesso à Internet é restrito a uma lista de endereços autorizados, uma "whitelist". A solução pedagógica varia de acordo com 
os formadores mas, geralmente, as situações de aprendizagem englobam momentos presenciais e não presenciais.

Relativamente ao "Virtual Campus" do Reino Unido, do ponto de vista tecnológico, Turley e Webster (2010) mostram que a plataforma foi desenvolvida com o objetivo de gerir as diferentes necessidades das pessoas reclusas, que têm acesso seguro a um conteúdo específico, constante de uma "whitelist". Este sistema permite, ainda, ser criado um e-portefólio com o perfil e os trabalhos desenvolvidos. Este e-portefólio acompanha o/a formando/a em caso de transferência de estabelecimento prisional ou de libertação da prisão.

Na Noruega, a rede IFI - "Internet for inmates" serve a totalidade dos estabelecimentos prisionais. Este sistema utiliza recursos oriundos da Internet, organizados em categorias, sendo que as pessoas reclusas apenas têm acesso às categorias consideradas seguras (HAMMERSCHICK, 2010).

Quanto aos projetos com financiamento comunitário de duração limitada, que ocorreram em parcerias de vários países, destacam-se: o Partnership in Prison Education Learning in Networked Environments (PIPELINE) (Noruega, República Checa, Dinamarca, Alemanha, Roménia, Eslóvenia, Suécia, Reino Unido) e o Learning Infrastructure for Correctional Services - European Transfer (LICOS) (Alemanha, Noruega, Áustria, Espanha, Holanda e Hungria).

O projeto PIPELINE (2005-2007), de acordo com a European Prison Education Association (EPEA, s/d), teve como objetivo a melhoria da educação prisional na Europa, através do recurso às TIC por reclusos/ as e formadores/as.

O projeto LICOS (2008-2010) objetivou construir um framework para a implementação de sistemas de eLearning na educação em contexto prisional (LICOS, 2010). Os princípios do modelo pedagógico desenvolvido por este projeto basearam-se nos conceitos de construtivismo, aprendizagem colaborativa e estímulo à curiosidade.

Em geral, as experiências partilhadas pelos responsáveis pelos projetos referidos, dão conta da preocupação com as questões pedagógicas, bem como com as questões tecnológicas, que incluem as medidas de 
segurança a serem tomadas. Como principais recomendações resultantes dos projetos, destacamos:

- A necessidade de ter em atenção a qualidade e diversidade da oferta formativa com recurso às tecnologias e a formação das pessoas que assumem o papel de tutor/a/moderador/a;

- A possibilidade de melhoria dos processos de educação/formação nas prisões por meio do desenvolvimento de competências digitais pela interação num ambiente "não escolarizado" que não esteja associado com a má experiência escolar prévia de alguns formandos;

- A necessidade de trabalho colaborativo e em rede entre todos os intervenientes (formandos, formadores e os diversos profissionais que atuam nas prisões);

- A necessidade de haver mais investigações acerca dos resultados e dos processos de aprendizagem através do eLearning em contextos prisionais.

Apesar das vantagens que podem ser atribuídas ao recurso ao eLearning em estabelecimentos prisionais (EPEA, s/d) - tais como a possibilidade de desenvolvimento de competências digitais, o trabalho em rede, o aumento da autoestima - é preciso ter em atenção os seus limites, bem como as soluções encontradas para ultrapassá-los. Lockitt (2011) analisou projetos implementados nas prisões da Noruega, Suécia e da Alemanha e identificou as seguintes dificuldades:

- Com a tecnologia: uso não efetivo, acesso restrito, carência de recursos;

- Estabelecimento prisional: processos de admissão da formação e dos formadores, escassez de liderança, penas de prisão de curta duração, falta de sensibilização acerca do potencial das tecnologias; 
- Formação: ausência de continuidade entre os currículos do interior e os do exterior da prisão, falta de um currículo comum e oferta limitada;

- Pessoas reclusas: escassez de motivação, falta de formação básica, inexistência de confiança/ receio das tecnologias.

Da análise do que foi exposto anteriormente, depreende-se que, para que se tire partido das vantagens e para que se conheçam e se ultrapassem as dificuldades relativas ao eLearning em contexto prisional, é fundamental um conhecimento aprofundado dos contextos locais e das situações de aprendizagem específicas para que se possam desenvolver projetos compatíveis com os ideais da inclusão digital e da justiça social, sendo necessário reconhecer as diferenças de forma a promover o acesso e a participação nestes ambientes de formação (MONTEIRO; BARROS: LEITE, 2015).

A lógica de acesso e, simultaneamente, de garantia de condições de participação e de sucesso foram tidas em consideração no desenho e implementação de um projeto de eLearning a que este artigo se refere e que ocorreu num estabelecimento prisional português localizado no Norte de Portugal.

\section{Metodologia}

O estudo realizado seguiu uma orientação qualitativa, sustentado na técnica de análise de conteúdo (BARDIN, 1995; QUIVY; CAMPENHOUDT, 1992; BOGDAN; BIKLEN, 1994; STRAUSS; CORBIN, 1998), de dados recolhidos das formandas/reclusas. Este processo, de acordo com Miles e Huberman (1984), consiste em reduzir os dados, de modo a permitir fazer inferências a partir deles. A opção por esta orientação deve-se ao reduzido número de sujeitos participantes no estudo e a necessidade de conhecer em profundidade, as suas percepções pessoais. 
Para alcançar os objetivos formulados de conhecer as formandas, as suas experiências no âmbito da aprendizagem ao longo da vida, incluindo as percepções sobre as vantagens e desvantagens da formação em regime de eLearning, os dados foram recolhidos através de um inquérito por questionário e por um focus group, isto é, uma técnica de entrevista em grupo que envolve a discussão estruturada a partir de temas com o objetivo de partilhar e clarificar diferentes pontos de vista, sendo a interação moderada por um ou mais investigadores (GREENBAUM, 1998; KRUGER, 1995). Este focus group realizou-se presencialmente no estabelecimento prisional onde decorreu a formação.

Numa fase inicial, em janeiro de 2015, as dez formandas/reclusas (Formanda 1, Formanda 2, Formanda 3, ... Formanda 10) preencheram o questionário com oito questões abertas acerca da aprendizagem ao longo da vida, percepções iniciais e expectativas relativas à formação em eLearning que iriam vivenciar.

No mês de setembro de 2015, oito formandas/reclusas (F1, F2, F3, F4, F5, F6, F7 e F8) participaram do focus group que teve por objetivo conhecer as suas percepções acerca das potencialidades e limites da formação em curso. Os procedimentos levados a cabo para a realização do focus group foram:

- Pedido de autorização ao estabelecimento prisional e agendamento da reunião;

- Convite às dez formandas, sendo que oito aceitaram participar após o esclarecimento dos objetivos e assinatura do consentimento informado;

- Elaboração de um plano com os tópicos a serem abordados (satisfação com a formação, questões técnicas e pedagógicas, impacto da formação na vivência e rotina na prisão, projeção do impacto da formação no futuro);

No decorrer da discussão foi obtido o consentimento para gravar em áudio, sendo posteriormente transcrita. A moderação foi feita por 
três investigadores. Uma investigadora propôs os temas a partir de perguntas (a começar por perguntas simples e gerais e sempre que preciso, especificava tentando clarificar as opiniões e estimular a participação de todas), outra investigadora observava, complementava e fazia perguntas afim de pedir um maior aprofundamento de respostas, quando necessário e o investigador registava as ideias principais e fazia apontamentos. Após a transcrição dos dados, estes foram analisados pela técnica de análise de conteúdo.

É importante ressaltar que as formandas foram ouvidas e as suas opiniões foram tidas em consideração em todas as etapas da concepção, desenvolvimento e implementação da formação. Foram consideradas, ainda, questões éticas, designadamente a autorização formal do estabelecimento prisional e a assinatura do consentimento informado, sendo garantida, ainda a confidencialidade na divulgação dos resultados.

\section{Caracterização das participantes e do ambiente de aprendizagem}

As dez formandas que participaram do estudo têm idades compreendidas entre os 21 anos e os 53 anos. Quanto ao nível de escolaridade, uma formanda concluiu o $2 .^{\circ}$ ciclo do ensino básico, três formandas concluíram o $3 .^{\circ}$ ciclo do ensino básico, três formandas concluíram o secundário e três formandas concluíram um curso superior ${ }^{4}$. Quanto à situação profissional anterior à detenção, duas afirmaram ser estudantes, uma desempregada, uma funcionária pública, uma advogada, uma auditora, uma monitora de desenho e de pintura, uma operária — sendo que duas não responderam a esta questão de caraterização. Relativamente ao estado civil, uma é viúva, duas são casadas, três solteiras e quatro são

4 O ensino básico em Portugal corresponde ao ensino fundamental no Brasil, o 2.․ ciclo do ensino básico, engloba o 5. e 6. anos de escolaridade e o 3.. ciclo engloba o 7., 8. e 9. anos de escolaridade. $\mathrm{O}$ ensino secundário corresponde ao ensino médio no Brasil. 
divorciadas ou separadas. O tempo de detenção varia dos 15 dias aos 7 anos e meio e a duração da pena de 4 anos e meio aos 21 anos.

A formação decorreu nos anos de 2015 e início de 2016 através da plataforma Moodle concebida especificamente para o projeto em questão, sendo as questões de segurança asseguradas por uma grande empresa de telecomunicações. O acesso à Internet no estabelecimento prisional era limitado ao ambiente organizado através de módulos de aprendizagem.

O ambiente foi formado pelos seguintes módulos:

- Ambientação: "Ser estudante online”, com duração de 25h;

- Informática básica: Word, Excel e PowerPoint, com 25h cada módulo;

- Empreendedorismo, com duração de 25h.

Cada módulo foi organizado em tópicos, por conteúdos - que continham conteúdos em diferentes formatos (texto, áudio e visual). As atividades foram propostas de forma a permitir uma diversidade de caminhos para que os resultados de aprendizagem fossem alcançados. As tarefas exigiam a mobilização de competências cognitivas (apresentação, domínio e resposta a questões sobre temas específicos através das ferramentas "questionário", "teste" e "submissão de trabalhos"), sociais (fóruns de apresentação e de discussão) e pessoais (situações em que havia a necessidade de análise de situações, sentido crítico, iniciativa, autonomia e autogestão do tempo e das aprendizagens).

Tendo em consideração o tamanho reduzido da amostra e a especificidade do contexto em estudo, não se pretende produzir generalizações, apenas fornecer pistas para o debate e para a reflexão futura acerca desta situação complexa e onde interagem diversos fatores igualmente importantes, tais como: pedagógicos, económicos, pessoais, culturais, tecnológicos e institucionais. Como é sabido, os estabelecimentos prisionais estão sujeitos a regras rígidas que têm em vista a garantia da segurança e o cumprimento da pena privativa de liberdade mas, por outro 
lado, pretendem promover também condições de reinserção e de ressocialização através da educação e da formação.

Os dados recolhidos através do questionário e do focus group serviram de base para a reflexão acerca dos resultados que passamos a apresentar neste artigo.

\section{Resultados}

\section{Fatores que contribuem para o recurso ao elearning em contexto prisional}

Para identificar a percepção acerca dos fatores que contribuem para o recurso ao eLearning em contexto prisional, as participantes foram interpeladas, através do questionário, sobre o que as motiva a frequentar ações de formação ao longo da vida e o papel do eLearning neste processo. Posteriormente, através do focus group as formandas/reclusas emitiram a sua opinião relativamente à ação que viveram e a que se reporta este artigo.

No que diz respeito aos fatores que as motivaram a frequentar ações de formação, os mais referidos por estas formandas/reclusas, através do questionário, foram: "Aprender mais e adquirir conhecimentos"(7 referências); "investimento no futuro" (1 referência); "ocupação" (1 referência); "valorização pessoal"(2 referências); "relações interpessoais" (1 referências), o que se confirma pelas seguintes afirmações:

Para adquirir mais conhecimentos. (F2)

Porque quero aprender mais e completar o meu futuro. (F4)

Sempre que tenho oportunidade de me inscrever em ações de formação, aproveito para aumentar os meus conhecimentos e aproveito para desenvolver as relações interpessoais, e de realização pessoal. (F7)

Quanto ao papel do eLearning na formação, a maioria das participantes (7 referências) acredita que este é um meio credível de formação. 
Como vantagens desta modalidade de ensino-aprendizagem, as formandas referiram: "acesso à aprendizagem (2 referências)"; "flexibilidade de horário" (2 referências); "reforço da autoestima" (1 referência); "trabalho em parceria" (1 referência); "integração social e laboral” (1 referência). As vantagens enunciadas vão ao encontro dos resultados obtidos pelos projetos PIPELINE (GHD, 2010) e (LICOS, 2010).

Durante o focus group foram referidas algumas vantagens da formação em eLearning, tais como as aprendizagens efetuadas, o aumento da familiarização com as TIC, o desenvolvimento da autonomia, o aumento da autoestima e o sentimento de capacidade de aprender, evidenciados nas seguintes afirmações:

Eu tenho ideias de abrir um restaurante em paralelo com o meu trabalho, a minha profissão e achei giríssimo aprender a fazer as contas, as multiplicações, as percentagens. Foi um bocado difícil para mim, sinceramente, conseguir nunca esquecer de clicar na cruzinha para fazer as operações. (F3) A nossa vontade muda. Eu falo por mim, há tanto tempo tive parada em relação a qualquer coisa como estudar, isto veio mudar a minha perspetiva, até pensar que era possivel. (F2)

Eu pensava que, se calhar, era mais burra do que sou, por exemplo. (...)Eu ganhei um bocadinho mais o gosto de estudar, se calhar, quem sabe poderei entrar para a faculdade... (F6)

As vantagens enunciadas alinham-se com os resultados dos projetos europeus anteriormente apresentados e corroboram a ideia de Lockitt (2011) quando refere que o recurso ao eLearning nas prisões pode contribuir para o aumento das oportunidades de aprendizagem através de uma formação personalizada, flexível e contínua.

\section{Barreiras ao eLearning no contexto prisional}

Para ter conhecimento das barreiras que o recurso ao eLearning enfrenta em contexto prisional, as formandas/reclusas foram 
questionadas acerca dos fatores que dificultam a frequência de ações de formação, em geral e do percurso pessoal de aprendizagem.

No que se refere aos fatores que dificultaram a frequência de ações de formação, as formandas, no questionário, reportaram-se à situação presente e referiram: "burocracias" (1 referência); "reclusão" (3 referências); "receio de errar" (1 referência); "falta de experiência" (1 referência); "falta de vontade pessoal" (1 referência). A seguinte afirmação dá conta de alguns destes fatores:

Na situação em que me encontro, privada da liberdade, é tudo muito restrito e todos os acessos muito limitados. O pouco que se consegue ter é muito condicionado. Se estivesse noutra situação, nada me impedia desde que tivesse vontade de a fazer. (F6)

Ainda no questionário, quando questionadas acerca do percurso de aprendizagem ao longo da vida, houve descrições de experiências menos agradáveis na escola e ao próprio rendimento escolar. As formandas/ reclusas referem-se à escola como "uma altura complicada" (Formanda 7) e duas formandas referiram não gostar de estudar.

Durante a discussão ocorrida no focus group, as formandas/reclusas também se referiram a algumas dificuldades sentidas. As dificuldades evidenciadas foram, igualmente, questões pessoais como a desmotivação, a ansiedade, a falta de bases em informática e a dificuldade de conciliar as tarefas com o trabalho na prisão. A estas dificuldades acrescentaram outras relacionadas com questões pedagógicas, como, por exemplo, excesso de tarefas, falta de acompanhamento ou falta de interesse em determinado conteúdo. Dificuldades relacionadas com questões institucionais, como o acesso restrito à Internet, foram também referidas. Disto são exemplo as seguintes afirmações:

... a minha dificuldade no meio do curso foi de mim mesma. Quando eu não estou bem comigo mesma, não consigo fazer nada, ou seja, a partir do momento em que fui de precária, perdi a paciência para o portátil, esquece. (F1) 
Identifico, um bocadinho, com o que a F1 estava a falar de ansiedade e..., pronto. Houve um dia ou outro que não estava, não fui de precária, mas tinha outras preocupações na cabeça, e nessa manhã por mais que eu quisesse, não conseguia estar atenta nem para aprender, nem para assimilar... (F6)

É lógico que eu não estava habituada porque eram muitos trabalhos, também. Uma ficha com três trabalhos, para quem tem uma base só, aprender as funções, o que querem que a gente faça (F6).

Os fatores enunciados por estas mulheres reclusas coincidem, parcialmente, com os resultados do relatório apresentado por Hawley, Murphy e Souto-Otero (2013), quando referem que as principais razões que justificam a não participação em aprendizagem ao longo da vida em estabelecimentos prisionais são: falta de motivação para aprender; más experiências anteriores de aprendizagem; maiores incentivos para o trabalho no interior do estabelecimento prisional do que para o estudo; limitado número de vagas; incompatibilidade com a duração da pena; e falta de diversidade da oferta formativa.

Relativamente às barreiras enunciadas por Lockitt (2011), a opinião das formandas/ reclusas é coincidente com as dificuldades relacionadas com as tecnologias e com os próprias pessoas em reclusão.

\section{Conclusões}

O contexto político europeu advoga um maior investimento no desenvolvimento pessoal dos adultos através da aprendizagem ao longo da vida e da aquisição de competências necessárias à participação na sociedade. Neste sentido, é imprescindível a intervenção junto aos grupos menos favorecidos, como as pessoas em situação de reclusão, situação que tem justificado o desenvolvimento de iniciativas em alguns países (MONTEIRO; BARROS: LEITE, 2015). Por outro lado, as rápidas transformações do mundo globalizado exigem o desenvolvimento constante de novas competências, o que tem vindo a gerar novas desigualdades 
educativas que reforçam a situação de exclusão social na qual muitas pessoas se encontram. A competência digital, considerada pela União Europeia como competência-chave para a aprendizagem ao longo da vida, enquadra-se nestas novas competências, cuja falta contribui para a manutenção das desigualdades.

Considerando que o recurso às TIC na educação/formação de adultos não é neutro e, por si só, não soluciona os problemas advindos das desigualdades sociais, mas, por outro lado, reconhecendo a necessidade de que se estudem formas alternativas de diversificar, flexibilizar e personalizar a oferta formativa, foi realizada e analisada uma formação que recorreu ao eLearning num ambiente prisional. Desta formação foram recolhidos dados sobre a visão das formandas/reclusas no que diz respeito às vantagens e aos limites desta modalidade de aprendizagem.

As vantagens referidas estão relacionadas com a aquisição de novas aprendizagens, o aumento da autoestima e da percepção da capacidade de aprender, assim como o acesso aos meios tecnológicos e a possibilidade de participar de modo paritário num ambiente digital.

Os limites do eLearning em contexto prisional identificados estão relacionados com as características individuais das reclusas, a nível das suas experiências, atitude e motivação); institucionais como o ambiente prisional ou as condições laborais; tecnológicas, a nível do acesso restrito e da segurança; pedagógicas relacionadas com a metodologia, conteúdos de ensino e acompanhamento.

Considerando o princípio de justiça social (CONNELL, 2012; BOLÍVAR, 2012) como processo, como um modelo democrático que inclui a participação em diferentes instituições sociais e culturais (YOUNG, 1990), defende-se que a inclusão digital possa ser considerada um "bem primário", ou seja um elemento necessário a todos os cidadãos (RAWLS, 2001) para que possam ter acesso, interagir com iguais direitos, participar e configurar ambientes culturais digitais. Este bem cultural deve, portanto, ser redistribuído com equidade, de forma que se reconheçam e se considerem as diferenças e as necessidades dos diferentes grupos sociais, independentemente do seu género, crenças, etnia ou situação pessoal e 
social. Em síntese, deseja-se que a divulgação deste estudo possa contribuir para que outras iniciativas sejam tomadas e que seja alargado o debate em torno da formação em contextos prisionais.

\section{Referências}

ABRANCHES, S. Prefácio: a educação nas trilhas do mundo digital. In: ALMEIDA, M.; ALVES, D. R,; LEMOS, S. (Orgs). Web currículo: aprendizagem, pesquisa e conhecimento com o uso de tecnologias digitais. São Paulo: Letra Capital, 2014. p. 7-12.

AYERS, W.; QUINN, T.; STOVALL, D. (Eds.) Handbook of social justice in education. New York: Routledge, 2009.

BARDIN, L. Análise de conteúdo. Lisboa: Edicões 70, 1995.

BOGDAN, R.; BIKLEN, S. Investigação qualitativa em educação: uma introdução à teoria e aos métodos. Porto: Porto Editora, 1994.

BOLÍVAR, A. Justicia social y equidad escolar: una revisión actual. Revista Internacional de Educación para la Justicia Social (RIEJS), v. 1, n. 1, p. 9-45, 2012.

CASTELLS, M. A sociedade em rede. Lisboa: Fundação Calouste Gulbenkian, 2002. CONNELL, R. W. Schools and social justice. Philadelphia: Temple University Press, 2012.

CONSELHO DA UNIÃO EUROPEIA. Communication from the commission Europe 2020: A strategy forsmart, sustainable and inclusive growth, 2010. Disponível em: <http://eurlex.europa.eu/LexUriServ/LexUriServ.do?uri=COM:2010:2020:FIN: en:PDF > Acesso em 12 dez. 2014.

CONSELHO DA UNIÃO EUROPEIA. eEurope 2002: An information society for all. 2000. Disponível em http://eurlex.europa.eu/legalcontent/EN/TXT/PDF/?uri= CELEX:52000DC0330\&rid=13 Acesso em 12 dez. 2014. 
EPEA. European prison association. Disponível em: $<$ http://www.epea.org/category/resources/. Acesso em: 6 set. 2015.

FRASER, N. Scales of justice: reimagining political space in a globalizing world. Nueva York: Columbia, 2008.

FRASER, N. A justiça social na globalização: redistribuição, reconhecimento e participação. Revista Crítica de Ciências Sociais [Online], nº 63, 2002. Disponível em: < http://rccs.revues.org/1250 >. Acesso em: 8 set. 2015.

GAMARNIKOW, E. Educação, (in)justiça social e direitos humanos: combatendo desigualdades na globalização turbocapitalista. Revista Brasileira de Educação, v. 18, n. 52, 2013.

GORARD, S.; SELWYN, N. Towards a le@rning society? The impact of technology on patterns of participation in lifelong learning. British Journal of Sociology of Education, v. 26, n. 1, p. 71-89, 2005.

GREENBAUM, T.L. The handbook of focus group research. London: Sage Publications, 1998.

HAMMERSCHICK, W. Report on e-learning in European prisons - Concepts, organization, pedagogical approaches in prison education. 2010. Disponível em: http:// www.adameurope.eu/prj/3840/prj/08-lc-report-e-learning-in-prison-eu-10.pdf. Acesso em: $10 \mathrm{dez} .2014$.

HAWLEY, J.; MURPHY, I.; SOUTO-OTERO, M. Prison education and training in Europe: current state-of-play and challenges. 2013. Disponível em: <http:// ec.europa.eu/education/library/study/2013/prison_en.pdf $\rangle$. Acesso em: 5 jan. 2015.

HURTADO, C. N. Educación popular: una mirada de conjunto. Decisio, Pátzcuaro, p. 3-14, janeiro-abril, 2005.

KRUGER, R. Focus groups: a practical guide for applied research. Thousand Oaks, CA; Sage Publications, 1995. 
LICOS. E-learning in prison education in Europe. Recommendations for European policy makers. 2010. Disponível em: http://www.adam-europe.eu/prj/3840/ prj/33-lc-recommendationse-learning-prison-10.pdf. Consultado em: 1 nov. 2014.

LOCKITT, W. Technology in prisons. 2011. Disponível em: <http://www.wcmt.org. uk/sites/default/files/migrated-reports/797_1.pdf>. Acesso em: 1 dez. 2014.

MASIE, E. The Blended Learning Imperative. In: BONK. C.; GRAHAM, C. (Eds.), The handbook of blended learning: global perspectives, local designs. San Francisco: Pfeifer, 2006. p. 22-26.

MARTINS, M. Plataforma Educacional no Sistema Prisional - reintegração social 2.0. IBI- Institut fur Bildung in der Informationsgesellschaft. Disponível em: www.ibi.tu-berlin.de. Acesso em: 4 nov. 2014.

MILES, M. B.; HUBERMAN, M. A. Qualitative data analysis: a source book of new methods. London:Sage Publications, 1984.

MONTEIRO, A.; BARROS, R.; LEITE, C.. Lifelong learning through e-learning in european prisons: rethinking digital and social inclusion. INTED2015 Proceedings, 2015. p. 1038-1046.

MOREIRA, J. A.; NUNES, M. G; CAEIRO, D. Educação a Distância e eLearning no Ensino Superior em estabelecimentos prisionais: projeto de desenvolvimento em Portugal. In: MOREIRA, J. A.; ALVES, L. (Org.). Pedagogia e Aprendizagem com Tecnologias digitais em espaços abertos, inclusivos e em rede. Salvador da Bahia: EDUFBA, 2016. p. 59-75.

MUILENBURG, L.; BERGE, Z. Student barriers to online learning: a factor analytic study. Distance Education, v. 26, n. 1, p. 29-48, 2007.

MURILLO, J.; HERNÁNDEZ, R. Hacia un concepto de justicia social. Revista Iberoamericana sobre Calidad, Eficacia y Cambio en Educación, v. 9, n 4, 2011. Disponível em: https://www.uam.es/personal_pdi/stmaria/jmurillo/arts/reice/ vol9num4_art1.pdf. Acesso em: 5 set. 2015. 
OECD (Organization for Economic Co-operation and Development). Lifelong Learning for All. Paris: OECD, 1996.

PASSERINO, L. Indicadores de inclusão digital: uma análise dos multiletramentos propiciados em redes sociais online a partir da ótica do posicionamento. QUAESTIO, v. 13. n. 2, p. 7-32, 2011.

PAULSEN, M. F. Sistemas de educação online: discussão e definição de termos. In: KEEGAN, D. et al. (Eds.). E-learning: o papel dos sistemas de gestão da aprendizagem na Europa. Lisboa: Inofor, 2002. p. 19-31.

PREECE, J. Research in adult education and lifelong learning in the era of CONFINTEA VI. International Journal of Lifelong Education, v. 30, n. 1, p. 99-117. 2011.

QUIVY, R. E CAMPENHOUDT, L. V. Manual de Investigação em Ciências Sociais. Lisboa: Gradiva, 1992.

RAWLS, J. Justice as fairness: a restatement. Cambridge, MA: Belknap Press, 2001.

ROSENBERG, M. J. E-learning: strategies for delivering knowledge in the digital age. New York: McGraw-Hill, 2001.

STRAUSS, A.; CORBIN, J. Basics of qualitative research: techniques and procedures for developing grounded theory. 2. ed. Thousand Oaks: Sage Publications, 1998.

TURLEY, C.; WEBSTER, S. Implementation and Delivery of the Test Beds Virtual Campus Case Study, National Centre for Social Research. 2010. Disponível em <https://www.gov.uk/government/uploads/system/uploads/attachment_data/ file/31466/11-827-implementation-of-test-beds-virtual-campus.pdf $>$. Acesso em 5 jan. 2015.

UK GOVERNMENT DIGITAL SERVICE. Digital inclusion strategy. 2014. Disponível em: https://www.gov.uk/government/publications/government-digital-inclusion-strategy/government-digital-inclusion-strategy. Acesso em: 18 mar. 2014. 
UNESCO. Relatório Global sobre Aprendizagem e Educação de Adultos. Brasília: Instituto da UNESCO para a Aprendizagem ao Longo da Vida (UIL), 2010.

UNIÃO EUROPEIA. Council Resolution on a renewed European agenda for adult learning, 2011. Disponível em <http://eur-lex.europa.eu/legalcontent/EN/TXT/ PDF/?uri=OJ:C:2011:372:FULL\&from=PT> Acesso em: 7 jan, 2015.

UNIÃO EUROPEIA. Competências essenciais para a aprendizagem ao longo da vida. 2006. Disponível em < http://eur-lex.europa.eu/legal-content/PT/TXT/HT ML/?uri=URISERV:c11090\&from=PT> Acesso em: 7 jan, 2015.

WARSCHAUER, M. Technology and Social Inclusion: rethinking the digital divide. Cambridge, MA: MIT Press, 2004.

YOUNG, I. M. Justice and the politics of difference. New Jersey: Princeton University, 1990.

Recebido: 30/01/2016

Received: 01/30/2016

Aprovado: 06/03/2016 Approved: 03/06/2016 
